\title{
BMJ Open Retrospective cohort analysis of real-life decisions about end-of-life care preferences in a Southeast Asian country
}

\author{
Woan Shin Tan, ${ }^{\oplus 1,2,3}$ Ram Bajpai, ${ }^{\oplus 1}$ Andy Hau Yan Ho, ${ }^{1,4,5}$ Chan Kee Low, ${ }^{6}$ \\ Josip $\operatorname{Car}^{\oplus 1,7}$
}

To cite: Tan WS, Bajpai R, Ho AHY, et al. Retrospective cohort analysis of real-life decisions about end-of-life care preferences in a Southeast Asian country. BMJ Open 2019;9:e024662. doi:10.1136/ bmjopen-2018-024662

- Prepublication history for this paper is available online. To view these files, please visit the journal online (http://dx.doi. org/10.1136/bmjopen-2018024662).

Received 8 June 2018 Revised 19 December 2018 Accepted 27 December 2018

Check for updates

(c) Author(s) (or their employer(s)) 2019. Re-use permitted under CC BY-NC. No commercial re-use. See rights and permissions. Published by BMJ.

For numbered affiliations see end of article.

Correspondence to Miss Woan Shin Tan; woan_shin_tan@nhg.com.sg

\section{ABSTRACT}

Objective To describe the end-of-life care preferences of individuals, and to examine the influence of age and gender on these preferences.

Design, setting and participants A retrospective cohort study was conducted. Participants included all adults ( $\geq 21$ years old) $(n=3380)$ who had completed a statement of their preferences as part of a national Advance Care Planning (ACP) programme in Singapore. Data were extracted from the national and Tan Tock Seng Hospital ACP database.

Main measures End-of-life care preferences were obtained from the ACP document and differentiated by health status (healthy, chronically ill or diagnosed with advanced illnesses). To analyse the data, descriptive statistics and logistic regression analysis were used. Results Across healthy and chronically ill patients, the majority did not opt for cardiopulmonary resuscitation (CPR) or other life-sustaining measures. Among individuals with advanced illnesses, 94\% preferred not to attempt CPR but $69 \%$ still preferred to receive some form of active medical treatment. Approximately $40 \%$ chose to be cared for, and to die at home. Age and sex significantly predict preferences in those with advanced illnesses. Older age ( $>=75$ years) showed higher odds for home as preferred place of care (OR 1.52; $95 \% \mathrm{Cl} 1.23$ to 1.89) and place of death (OR 1.29; $95 \% \mathrm{Cl} 1.03$ to 1.61) and lower odds for CPR (OR $0.31 ; 95 \% \mathrm{Cl} 0.18$ to 0.54 ) and full treatment (OR $0.32 ; 95 \% \mathrm{Cl} 0.17$ to 0.62 ). Being female was associated with lower odds for home as preferred place of care (OR $0.69 ; 95 \% \mathrm{Cl} 0.57$ to 0.84 ) and place of death (OR 0.70; $95 \% \mathrm{Cl} 0.57$ to 0.85 ) and higher odds for full treatment (OR 2.35; $95 \% \mathrm{Cl} 1.18$ to 4.68 ).

Conclusion The majority preferred to not proceed with life-sustaining treatments, but there was still a strong preference to receive some form of limited treatment. Better understanding of end-of-life care preferences through ACP can better guide end-of-life care programme planning, and resource allocation decisions.

\section{INTRODUCTION}

Most societies that are experiencing a rapidly ageing population would encounter challenges in providing high quality end-of-life
Strengths and limitations of this study

- Examined real-life end-of-life care preferences of individuals across different health states.

- Comprehensive coverage of a large sample of patients who received care from seven acute care hospitals, and twelve different social care providers in Singapore.

- Examined the association of end-of-life care preferences with age and sex but was unable to examine the correlation with other covariates due to data limitation.

- Individuals who voluntarily completed their advance care plans could be less death avoidant.

- Prospective study will allow for gathering of more variables that influence end-of-life care preferences which this study lacks.

care to its population. In many jurisdictions, through a process of Advance Care Planning (ACP), an individual could designate a healthcare decision-maker, and specify decisions regarding life-sustaining treatments in the event of decisional incapacitation. Research has found ACP to empower patients with a greater peace of mind, ${ }^{1}$ improve the level of agreement with regards to end-of-life care between patient and surrogate, reduce decisional conflict ${ }^{2}$ and improve their satisfaction with care. ${ }^{3}$ The likelihood of dying at their preferred place was also higher among individuals who had completed an $\mathrm{ACP}^{4}$; the transition between acute and terminal care is often smoother. ${ }^{5}$ ACP was also associated with avoiding or reducing unnecessary life-sustaining treatments, ${ }^{14}$ increasing the incidence of out-of-hospital and out-of-intensive care, and increasing the probability of dying at home. ${ }^{6-9}$

With this perspective, the Singapore government launched a comprehensive national ACP programme, 'Living Matters', 
in 2011. 'Living Matters' is based on the Respecting Choices programme at the Gundersen Health System in Wisconsin, USA. Primarily, the programme aims to systematise the elicitation and documentation of medical and care preferences ${ }^{10}$ with a longer-term goal of normalising death and dying conversations in the community. ${ }^{11} 12$ Listed among populations that are ageing most rapidly in the world, this is a timely effort, as the need to cater for healthcare, including end-of-life care of the population, is expected to intensify alongside the doubling of the elderly population. ${ }^{13}$

Surveys have been conducted locally to profile the end-of-life care preferences across different patients and community-based samples. ${ }^{14-17}$ However, surveys often require individuals to respond to a single question about their preferred place of death, based on a hypothetical end-of-life scenario ${ }^{18}$ without having to trade off against other priorities or account for other than one's personal concerns. Therefore, choices elicited through a survey could reflect what is preferred under more 'ideal' circumstances. Since an illness impacts the individual biologically as well as socially, ${ }^{19}$ the survey process may not mirror real-life decision-making processes well. ${ }^{20}$

Therefore, in this article, we review the demographics and end-of-life care preferences, as documented in an Advance Care Plan. Given that end-of-life care preferences could differ across different health states and over one's life cycle, ${ }^{21}$ preferences are profiled according to the health status of those expressing them. Additionally, we also examined the effect of age and gender on stated preferences.

\section{METHODOLOGY \\ ACP programme}

The 'Living Matters' programme comprised three integrated components': provision of patient educational materials ${ }^{2}$; trained and certified ACP facilitators who assist individuals with $\mathrm{ACP}^{3}$; development of an IT system to enable easily storage, and retrieval of ACP forms. ${ }^{22}{ }^{23}$ The programme has adopted a staged approach that considers a person's state of health and allows ACP to be conducted in phases across one's lifetime. The conversations can then be individualised based on one's health status, which is broadly categorised as healthy, diagnosed with complex chronic illnesses or diagnosed with advanced illnesses.

Currently, referral to ACP and the staging of one's health status is largely based on clinical judgement. Individual clinicians also assess the individual patient's readiness to discuss end-of-life care issues. In practice, a social care or healthcare professional may facilitate a conversation between the patient and his/her family members to explore his/her values, beliefs and how this impacts preferences towards medical care at the end of life. ACP is not legally binding in Singapore and, therefore, there is no need to engage a lawyer for its discussion or documentation. ${ }^{24}$ All participating patients are encouraged to identify a substitute decision-maker (SDM) who can

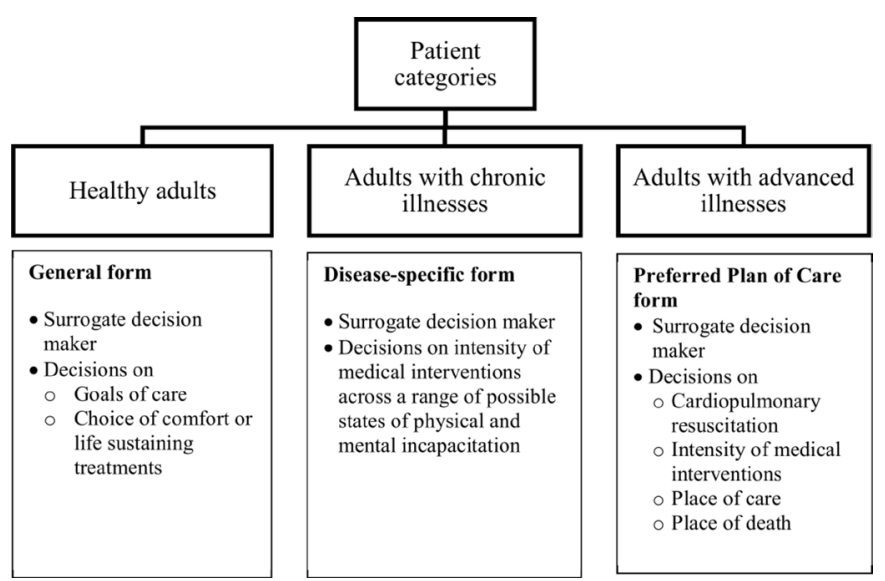

Figure 1 End-of-life care decisions by health status.

make healthcare decisions on their behalf in the event of incapacitation.

Different questions and standardised forms apply to each of the three health states (healthy, chronically ill, with advanced illness) (figure 1). Individuals identify a substitute decision-maker and also establish the goals of care relevant to their disease stage. They are intended to update their decisions as they transit health states. For instance, questions regarding disease-related complications are not applicable to a healthy individual whereas, for an individual with a poor prognosis, questions related to disease-related complications may no longer be applicable. Rather, they may be concerned about care during the terminal phase.

End-of-life care preferences are documented in an IT system after obtaining the patient's concurrence that they accurately reflect their decisions. These recorded preferences are accessible to different providers across the acute care continuum.

\section{Study design and population}

This is a retrospective cohort study that included all individuals aged 21 years and above, who have completed their ACP between January 2011 and December 2015 across all participating acute care hospitals, specialist care centres and social care providers in Singapore.

\section{Patient and public involvement}

Patients were not involved in the design of the study although end-of-life care preferences documented as part of routine clinical care were aggregated and reported in this study. As only anonymised data were analysed, data were not disseminated to the patients.

\section{Ethics and consent}

Ethics approval was obtained. As this is a retrospective database study, written informed consent was waived .

\section{Elicited preferences by health status}

There were three different forms, general, disease specific, and the preferred plan of care form, to cater to individuals at different health stages (healthy, chronically ill, advanced illness). 
For healthy adults, they were asked about their preferences related to the goals of care when the probability of recovery or survival is low. The choices provided were: 'make comfort the goal of my care and do not prolong my life in this condition' or 'continue to provide all necessary life-sustaining treatment until outcomes happen to me which I find unacceptable'.

For individuals with chronic conditions, the wishes documented in an ACP form specifies preferences about cardiopulmonary resuscitation (CPR) during cardiac arrest and decisions about treatment options if they were to develop serious complications with (1) a low likelihood of survival, (2) a high likelihood of survival but might become immobile and unable to communicate or (3) a high likelihood of survival but might suffer from permanent cognitive impairment. The choice categories include 'all treatment I need to live as long as I can', 'stop all efforts to keep me alive, allow natural death to happen' and 'unsure'.

For individuals with advanced illnesses, they were asked about their CPR preferences, decisions related to medical intervention (comfort, limited additional interventions, full treatment), place of care and place of death. Under the current programme, full treatment considers intubation, mechanical ventilation and cardioversion. Medical management may also include transfer to intensive care if indicated. Limited additional interventions include comfort measures and may also include oral or intravenous medications. While non-invasive ventilation support is acceptable, endotracheal intubation or long-term life support measures, including admission to intensive care units, are not. Comfort measures include reasonable measures made to offer food and fluids. Medications, oxygen and other measures may be used as needed for comfort, but it does not include intubation.

For place of medical treatment or care, individuals could opt for the home, hospice, nursing home, hospital, a trial of treatment in their homes before considering transfer to a hospital or a hospice and a trial of treatment in the hospice or nursing home before transfer to a hospital. The documentation also allowed the individual to indicate 'no preferences' and 'others'. For place of death, individuals are asked where they would wish to be if they were left with 2-3 days of life. They could opt for either the home, hospital, hospice or nursing home, and two or more alternatives such as home or hospital, and home or nursing home or hospital.

\section{Measures and data extraction}

We extracted data on available personal characteristics of patients (age/gender) and preferences from the national ACP IT system and the Tan Tock Seng Hospital ACP database. Data fields related to the nomination of a substitute decision maker(s), preference about the administration of CPR in the event of a cardiac arrest and end-of-life care preferences were extracted. In addition, for patients diagnosed with advanced illnesses, we extracted their preferences for place of care and death as well.

To ascertain whether the individuals were deceased, the data were linked to death-related data from the National Registry of Birth and Deaths. Every Singaporean resident is issued with a National Registration Identity Card (NRIC) number. For this study, a project unique identifying number (PUIN) was generated for each NRIC by a third-party vendor, who was not involved in the analysis of the data. The PUIN was then used to link data belonging to each individual person across the data sets.

\section{Data analysis}

Descriptive statistics were used to profile the sample and to summarise the basic characteristics of the data. Frequency distribution tables were created to profile the characteristics of the study samples and to describe the documented end-of-life care preferences. A $\chi^{2}$ test was used to determine whether a statistically significant relationship exists between two or more categorical variables.

We examined the independent effects of age and gender on four different end-of-life care statement of preference. We dichotomised the preferences for: (1) CPR ('attempt' or 'do not attempt'), (2) medical intervention ('treatment' or 'comfort measures'), (3) preferred place of medical treatment ('home' or 'others') and (4) preferred place of death ('home' or 'others'). Multivariable logistic regression was performed to investigate the relationship between age and sex with these preferences. Adjusted odds ratios (ORs) were estimated from multivariable models and reported with corresponding 95\% confidence intervals (CIs). All statistical tests were conducted using Stata V.12, ${ }^{25}$ and a two-sided $p$ value of 0.05 was set as the level of statistical significance.

\section{RESULTS}

A total of 3380 completed ACP documents were captured in the databases, with approximately $90 \%$ completed in acute hospitals. The patient characteristics can be seen in table 1 . Sixty per cent of the patients were aged 75 years and above, and there was demographic variation across the three types of ACP, with younger age profiles for those who completed the general and disease-specific forms. Among all individuals who completed the ACP, 53.2\% (1798/3380) were deceased as of 31 December 2015, with the highest share for individuals with advanced illnesses. The overall median time between ACP completion and death was 7.27 months (95\% CI 6.35 to 8.18); $63.2 \%$ completed ACP within 3 months prior to death, $52.9 \%$ within 6 months and $42.3 \%$ within 12 months.

\section{Documented preferences}

Data related to preferences for end-of-life care are represented in table 2. For healthy individuals who had completed the general ACP, one in eight persons indicated a preference for life-sustaining treatment. For individuals with chronic illnesses, close to one in three opted for CPR 
Table 1 Profile of individuals by health status

\begin{tabular}{|c|c|c|c|c|c|c|}
\hline \multirow[b]{2}{*}{ Variable } & \multirow[b]{2}{*}{ Category } & \multicolumn{3}{|c|}{ Health status } & \multirow[b]{2}{*}{ Total (n, \%) } & \multirow[b]{2}{*}{$P$ value } \\
\hline & & $\begin{array}{l}\text { Healthy } \\
(\mathrm{n}, \%)\end{array}$ & $\begin{array}{l}\text { Chronic illness } \\
(\mathrm{n}, \%)\end{array}$ & $\begin{array}{l}\text { Advanced illness } \\
(\mathrm{n}, \%)\end{array}$ & & \\
\hline \multirow[t]{4}{*}{ Age } & $<55$ years & 77 (11.9) & $6(12.2)$ & $142(5.3)$ & $225(6.7)$ & $<0.001$ \\
\hline & 55-64 years & $193(29.9)$ & 14 (28.6) & 259 (9.6) & $466(13.8)$ & \\
\hline & $65-74$ years & 203 (31.4) & $17(34.7)$ & 445 (16.6) & $665(19.7)$ & \\
\hline & $\geq 75$ years & $173(26.8)$ & 12 (25.5) & $1839(68.5)$ & 2024 (59.9) & \\
\hline \multirow[t]{3}{*}{ Sex } & Female & $359(55.6)$ & 19 (38.8) & $1316(49.0)$ & $1694(50.1)$ & 0.001 \\
\hline & Male & $265(41.0)$ & $28(57.1)$ & $1335(49.7)$ & $1628(48.2)$ & \\
\hline & Missing & $22(3.4)$ & $2(4.1)$ & $34(1.3)$ & $58(1.7)$ & \\
\hline \multirow[t]{2}{*}{ Deceased } & Yes & $57(8.8)$ & 10 (20.4) & $1731(64.5)$ & 1798 (53.2) & $<0.001$ \\
\hline & No & 589 (91.2) & 39 (79.6) & 954 (35.5) & $1582(46.8)$ & \\
\hline Total & & 646 100.0) & $49(100.0)$ & $2685(100.0)$ & $3380(100.0)$ & \\
\hline
\end{tabular}

and life-sustaining treatment, even if the likelihood of surviving the complications of the illness were low or if they were to lose their ability to move around or communicate. However, only $16.3 \%$ opted for full treatment if they were to become mentally incapacitated because of their illness.

For individuals with advanced illnesses (Table 2), $5.7 \%$ opted for CPR and $5.1 \%$ opted for full medical intervention. The majority preferred the initiation of a limited trial of treatment, which would be continued with comfort measures if there was no clinical improvement. Approximately $43.6 \%$ of individuals preferred to receive treatment in their homes, but $77.4 \%$ of these individuals would consider being transferred to an acute hospital after a trial of care at home. Only $29.7 \%$ stated the hospital as their preferred site of care. For place of death, $40.4 \%$ preferred dying at home, and only $14.1 \%$ preferred the hospital. One highlight is that although only $4.1 \%$ did not state any preference or were unsure about the place of care, $23 \%$ of respondents did not indicate their preferences with regards to the preferred place of death.

\section{Relationship between patient and SDM}

The share of individuals who had appointed a substitute decision-maker varied across the three health states. The rates of nomination were, however, lower for those who were healthy or diagnosed with chronic illnesses. For those with advanced illnesses, only $6 \%$ of individuals did not identify a substitute decision-maker (table 2table 3). From table $4,78 \%$ of individuals nominated their immediate family (spouse, children, grandchildren) to speak on their behalf if they were incapacitated. Only a small percentage nominated non-related persons. Most ACP discussions also took place in the acute care setting.

\section{Relationship between preferred place of care and place of death}

Table 4 assessed the relationship between place of care and place of death. The results indicated that there was a high level of agreement and strong correlation in preferences related to being cared for at home and dying at home. Other than this, the place of care is not synonymous with where they would like to die at. Close to one in three individuals who preferred the hospital as the location of care had also opted for home as the place of death.

\section{Relationship between treatment preferences and patient profile}

As age and sex were not correlated with preferences for healthy and chronically ill individuals, the results were excluded. Table 5 illustrates the results from a logistic regression to assess the impact of age and sex on the preferences of those with advanced illnesses. Those aged 75 years and above were more likely to not opt for CPR and comfort measures, compared with younger individuals. Care at home or having a trial of care at home was the preferred option for the older age group. Similarly, older people exhibited a stronger likelihood of preferring to die at home. There were no significant gender differences in preferences for CPR. However, there was a higher likelihood of women opting for full treatment than comfort measures. This is also consistent with the relatively lower odds of choosing home as the site of care and place of death, compared with men.

\section{DISCUSSION}

This is the first study to have quantified actual preferences about end-of-life care, in a relatively large clinical sample in Singapore. Other published studies have adopted a survey design to elicit preferences as part of research. ${ }^{141526}$ The findings offered insights into decisions made under real-life situations, where the stated preferences were supposed to reflect goals of care of the individual. Singapore stands apart being an Asian country that is strongly influenced by Western culture where the people have a strong desire for independence together with a collectivist mentality. ${ }^{27}$ The results of this study 
Table 2 End-of-life care preferences in general and disease-specific ACP forms

\begin{tabular}{lr}
\hline Documented preferences & $\mathbf{n , ~ \% ~}$ \\
\hline Healthy individuals ( $\mathrm{n}=646)$ & \\
\multicolumn{1}{l}{ Appointment substitute decision maker } & $581(89.9)$ \\
\hline $\begin{array}{l}\text { Comfort measures } \\
\text { Life-sustaining treatments }\end{array}$ & $560(86.7)$ \\
$\begin{array}{l}\text { Individuals with chronic illness ( } \mathrm{n}=49) \\
\begin{array}{l}\text { Appointment first substitute decision } \\
\text { maker }\end{array}\end{array}$ & $35(71.4)$ \\
$\begin{array}{l}\text { Appointment second substitute decision } \\
\text { maker }\end{array}$ & $15(30.6)$ \\
\hline
\end{tabular}

Serious complication with low chance of survival
Full treatment
$16(32.7)$
Stop treatment
$31(63.3)$

Serious complication with loss of ability

to move around or communicate

$\begin{array}{ll}\text { Full treatment } & 15(30.6) \\ \text { Stop treatment } & 32(65.3)\end{array}$

Serious complication with mental incapacity

\begin{tabular}{|c|c|}
\hline Full treatment & $8(16.3)$ \\
\hline Stop treatment & $38(77.6)$ \\
\hline \multicolumn{2}{|l|}{ Cardiopulmonary resuscitation } \\
\hline Attempt & $14(28.6)$ \\
\hline Do not attempt & $19(38.8)$ \\
\hline $\begin{array}{l}\text { Do not attempt if doctor believes low } \\
\text { survival chances }\end{array}$ & $14(28.6)$ \\
\hline \multicolumn{2}{|l|}{ Individuals with advanced illness ( $\mathrm{n}=2685)$} \\
\hline $\begin{array}{l}\text { Appointment first substitute decision } \\
\text { maker }\end{array}$ & $2526(94.1)$ \\
\hline $\begin{array}{l}\text { Appointment second substitute decision } \\
\text { maker }\end{array}$ & $1357(50.5)$ \\
\hline \multicolumn{2}{|l|}{ Cardiopulmonary resuscitation } \\
\hline Attempt & $152(5.7)$ \\
\hline Do not attempt & $2511(93.5)$ \\
\hline $\begin{array}{l}\text { Do not attempt if doctor believes low } \\
\text { survival chances }\end{array}$ & $22(0.8)$ \\
\hline \multicolumn{2}{|l|}{ Medical intervention } \\
\hline Full treatment & $138(5.1)$ \\
\hline Limited additional interventions & $1851(68.9)$ \\
\hline Comfort measures only & $677(25.2)$ \\
\hline Unsure & $19(0.7)$ \\
\hline \multicolumn{2}{|l|}{ Preferred place of medical treatment } \\
\hline Home & $265(9.8)$ \\
\hline Hospital & $798(29.7)$ \\
\hline Nursing home & $166(6.2)$ \\
\hline Hospice & $131(4.9)$ \\
\hline
\end{tabular}

Continued

\begin{tabular}{|c|c|}
\hline Documented preferences & $\mathrm{n}, \%$ \\
\hline \multicolumn{2}{|l|}{$\begin{array}{l}\text { Trial of treatment before consider } \\
\text { transfer to hospital }\end{array}$} \\
\hline Home & $908(33.8)$ \\
\hline Nursing home & $269(10.0)$ \\
\hline Hospice & $28(1.0)$ \\
\hline Others (no preference, unsure) & $110(4.1)$ \\
\hline Missing & $10(0.4)$ \\
\hline \multicolumn{2}{|l|}{ Preferred place of death } \\
\hline Patient's home & $1084(40.4)$ \\
\hline Hospital & $379(14.1)$ \\
\hline Nursing home & $160(5.9)$ \\
\hline Hospice & $156(5.8)$ \\
\hline $\begin{array}{l}\text { Home or hospital/nursing home/ } \\
\text { hospice }\end{array}$ & $112(4.2)$ \\
\hline $\begin{array}{l}\text { Healthcare institution (hospital or } \\
\text { nursing home or hospice) }\end{array}$ & $177(6.7)$ \\
\hline Others (no preference, unsure) & $617(23.0)$ \\
\hline
\end{tabular}

ACP, Advance Care Planning; CPR, cardiopulmonary resuscitation.

could therefore be of relevance to other Asian countries that are also experiencing rapid socioeconomic and demographic transitions.

In our study, most individuals nominated their family members to speak on their behalf if they were incapacitated, which is similar to what was observed in other studies. ${ }^{28}$ Among healthy and chronically ill patients, the majority did not opt for CPR or other life-sustaining measures. Among those with advanced illness, more than 90\% preferred not to attempt CPR, but more than $70 \%$ still preferred to receive some form of active medical treatment at the end-of-life, rather than comfort care. In this national sample, approximately 4 in 10 chose to be cared for and to die at home. Other Singaporean studies examined the preferences of nursing home residents ${ }^{29}$ and those who received care in a day care centre. ${ }^{16}$ These studies similarly found that while most individuals did not opt for CPR, they did express a preference to receive some form of active treatment. ${ }^{169}$

In 2014, the Lien Foundation, a Singapore philanthropic house, commissioned a community-based survey to determine the death attitudes and the level of awareness about hospice and palliative care. The survey reported that $70 \%$ and $77 \%$ of the surveyed individuals would prefer to be cared for and to die at home, respectively. ${ }^{17}$ Preferences for medical treatment at home and for home deaths were significantly lower in our sample. Public opinions often do not coincide with the views of individuals who are close to the end of life..$^{20}$ Other research, such as those examining health state valuation, have pointed out the differences between these two groups, ${ }^{30}$ reflecting different priorities and changing experiences. The complexity of choices 
Table 3 Relationship with substitute decision maker

\begin{tabular}{|c|c|c|c|c|c|}
\hline \multirow[b]{2}{*}{ Type of substitute } & \multicolumn{3}{|c|}{ Health status } & \multirow[b]{2}{*}{ Total } & \multirow[b]{2}{*}{$P$ value } \\
\hline & $\begin{array}{l}\text { Healthy } \\
(\mathrm{n}, \%)\end{array}$ & $\begin{array}{l}\text { Chronic illness } \\
(\mathrm{n}, \%)\end{array}$ & $\begin{array}{l}\text { Advanced } \\
\text { illness (n, \%) }\end{array}$ & & \\
\hline Spouse & $185(28.6)$ & $8(16.3)$ & 320 (11.9) & $513(15.2)$ & $<0.001$ \\
\hline Child, child-in-law or grandchild & $230(35.6)$ & $20(40.8)$ & $1869(69.6)$ & $2119(62.7)$ & \\
\hline Other relatives and friends & $136(21.1)$ & $2(4.1)$ & $266(9.9)$ & 404 (12.0) & \\
\hline $\begin{array}{l}\text { Others (including healthcare } \\
\text { professionals) }\end{array}$ & $14(2.2)$ & $1(2.0)$ & $10(0.4)$ & $25(0.7)$ & \\
\hline Missing & $81(12.5)$ & $18(36.7)$ & $220(8.2)$ & 319 (9.4) & \\
\hline Total & 646 (100.0) & 49 (100.0) & $2685(100.0)$ & $3380(100.0)$ & \\
\hline
\end{tabular}

also grows as death draws near. ${ }^{31}$ When healthy participants are asked to make decisions regarding hypothetical scenarios about death and dying, the 'shock' or fear that he or she experiences ${ }^{32}$ about potentially dying in an unfamiliar environment could sway decisions towards the familiar, meaning the home. Juxtaposed against other priorities, such as pain and symptom management, and alleviating caregiver burden, the 'cost' of maintaining one's decision to die at home may also increase ${ }^{33}$ At the same time, the fear of the unfamiliar could decrease over time, as patients increasingly adapt to new living and care arrangements in other settings, such as nursing homes or hospices. ${ }^{34}$ One in five individuals have been found to change their preferences over time. ${ }^{18}$

We also found that, although the preferred place of care and place of death are related, they are not equivalent. While only a small percentage of individuals did not have strict preferences about where they are being cared for, almost one in four individuals expressed that they had no preferred place of death. Other studies have similarly indicated that these two dimensions are not equivalent, although healthcare professionals may use them interchangeably in practice. ${ }^{35}$

In our study, the time between ACP completion and death was 7.3 months. While there is no objective optimal timing, ${ }^{36}$ this is relatively shorter than the median times (14-37 months) reported in the literature. ${ }^{3738}$ Given that the discussion about preferences should occur before physical or mental incapacitation, earlier initiation can be beneficial to the patients. At the same time, it is important to strike a balance because conducting the ACP conversation too early when preferences are still unstable ${ }^{39}$ could lead to unrealistic choices based on hypothesised scenarios. ${ }^{37}$ ACP initiation should take into account patient and family receptivity and, ideally, precede major health deterioration that could lead to decisional incapacitation. ${ }^{40}$ Different diseases have different pathways of functional declines ${ }^{41}$ which also needs to be considered.

In our sample of patients with advanced illnesses, we found that age was positively associated with preferences to withhold life-sustaining treatments, which was similar to the findings of several studies. ${ }^{42}{ }^{43}$ We found that

Table 4 Preferred place of care and preferred place of death

\begin{tabular}{|c|c|c|c|c|c|c|c|c|}
\hline \multirow[b]{2}{*}{ Place of death } & \multicolumn{8}{|c|}{ Place of care } \\
\hline & Home & Hospital & Hospice & $\begin{array}{l}\text { Nursing } \\
\text { home }\end{array}$ & $\begin{array}{l}\text { Home to } \\
\text { hospital/ } \\
\text { hospice }\end{array}$ & $\begin{array}{l}\text { Hospice } \\
\text { to NH/ } \\
\text { hospital }\end{array}$ & Others ${ }^{\#}$ & Total \\
\hline Home & $90.9^{\star *}$ & 31.1 & 9.9 & 5.4 & 57.3 & 12.1 & 12.7 & 40.4 \\
\hline Hospital & 0.8 & $30.3^{\star *}$ & 0.0 & 1.2 & 9.7 & 13.7 & 2.7 & 14.1 \\
\hline Hospice & 0.8 & 3.1 & $67.9^{N S}$ & 0.6 & 2.6 & 3.3 & 4.5 & 5.8 \\
\hline $\begin{array}{l}\text { Home or } \\
\text { hospital/nursing } \\
\text { home/hospice }\end{array}$ & 1.9 & 3.5 & 1.5 & 0.0 & $8.0^{\star \star}$ & 2.0 & 2.7 & 4.4 \\
\hline $\begin{array}{l}\text { Healthcare } \\
\text { institution }\end{array}$ & 0.4 & 4.4 & 4.6 & $6.6^{\star}$ & 1.2 & $30.3^{*}$ & 19.1 & 6.6 \\
\hline
\end{tabular}

${ }^{* *} \mathrm{p}<0.01 ;{ }^{*} \mathrm{p}<0.05$.

\# no preferences orunsure. 
Table 5 Multivariable logistic regression of preferences by age and sex with 2685 subjects with advanced illnesses

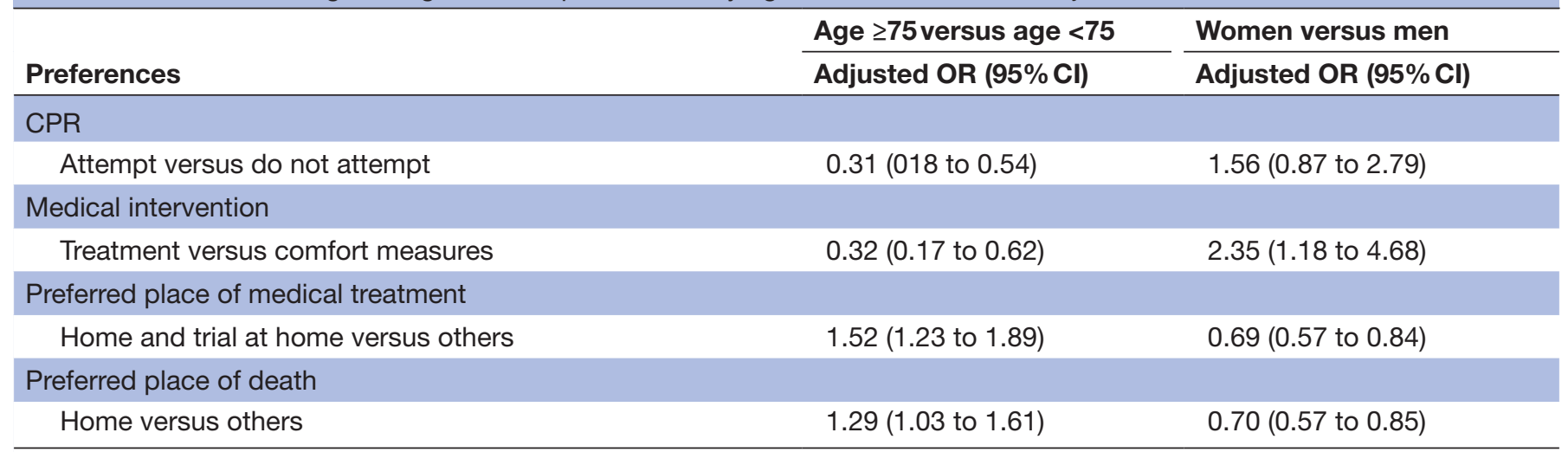

Model includes variables: age and sex.

CPR, cardiopulmonary resuscitation; PPC, preferred plan of care.

individuals older than 75 years were more likely to opt for the home as the place of care and death; but other studies reported that younger individuals more strongly prefer home as the place of care, ${ }^{44}$ or that age did not have a significant effect. ${ }^{45}$ Cultural differences, in the meaning assigned to the 'home' as a place of care and death, or even the availability of alternative palliative care facilities in different countries, could have resulted in the mixed evidence. For instance, due to the availability of inpatient palliative care units in Japan, older individuals had stronger preferences for the patient palliative care unit as the site of care than home. ${ }^{44}$ Our finding, that women were less likely to prefer to be cared for and die at home, was similarly reported in other studies. ${ }^{46} 47$ This could reflect the general longer life expectancy of women compared with men. This reduced likelihood of spousal support at the end of life could make home less preferred as an option. ${ }^{48}$

\section{Policy and practice implications}

Currently, efforts to implement ACP are focused on the elderly and those with advanced illnesses. Based on the numbers of completed disease-specific forms, the take-up by chronically ill individuals is very low. While better integration of ACP with chronic disease management efforts or more rapid expansion of ACP to the outpatient and community settings could assist in improving coverage, additional resources would concurrently be needed to assist hospitals to expand coverage to younger adults, and bringing ACP conversations forward in the life cycle of an individual. Building community awareness of and acceptance towards ACP will be crucial.

Policies should also consider a range of perspectives and preferences, especially of subpopulations that they will most immediately affect. Preferences elicited from surveys can be viewed as an aspirational target that is achievable if practical barriers were eradicated. Additionally, due to the relatively high proportion of individuals who still preferred hospital as the location of care, policy-makers still need to focus on improving the end-of-life care experience in formal healthcare institutions, while also expanding home palliative care capacity to cater to those who preferred home as the first place of care and place of death.

\section{Limitations}

The sample comprised largely the patients receiving care in the acute care hospitals. As such, the results may not be generalisable for patients in the community care settings or to other individuals who have elected not to participate in ACP. Individuals who had completed the ACP documentation could be less death avoidant and, therefore, have different preferences compared with others. We were only able to examine the relationship between preferences and patient age and sex due to limited availability of data. Other studies ${ }^{49}$ have also highlighted the importance of the family and care context on care preferences. A recent systematic review ${ }^{50}$ highlighted the lack of research evidence on ethnicity and religion, which is also absent from this study. Future research should explore the influence of these pertinent elements including a closer examination of the influence of different illnesses (advanced malignancy, end-stage organ failure or neurodegenerative diseases) on end-of-life care preferences.

\section{CONCLUSION}

This study identified that most of the individuals in our sample, regardless of health status, preferred not to proceed with life-sustaining treatments across a spectrum of health scenarios. However, individuals with advanced illnesses still preferred to receive some form of active support, for example, non-invasive ventilation support or oral and intravenous drug administration. Our results imply that policies should consider home-based end-oflife care, and also actively focus on the quality of end-oflife care in hospitals, since many individuals still opt for them as the site of care.

\section{Author affiliations}

${ }^{1}$ Centre for Population Health Sciences, Lee Kong Chian School of Medicine, Nanyang Technological University, Singapore, Singapore 
${ }^{2}$ NTU Institute for Health Technologies, Interdisciplinary Graduate School, Nanyang Technological University, Singapore, Singapore

${ }^{3}$ Health Services and Outcomes Research Department, National Healthcare Group, Singapore, Singapore

${ }^{4}$ Psychology Programme, School of Social Sciences, Nanyang Technological University, Singapore, Singapore

${ }^{5}$ Research Department, Palliative Care Centre for Excellence in Research and Education, Singapore, Singapore

${ }^{6}$ Economics Programme, School of Social Sciences, Nanyang Technological University, Singapore, Singapore

${ }^{7}$ Global eHealth Unit, Department of Primary Care and Public Health, School of Public Health, Imperial College London, London, UK

Acknowledgements We would like to thank Dr Raymond Ng, Consultant, Department of Palliative Medicine, Tan Tock Seng Hospital, for contributing data that were used in the analysis. We would also like to acknowledge Mr Geronimo Jimenez and Dr Sng Ming Keat, Nanyang Technological University Singapore and other colleagues from the Agency for Integrated Care, and the Ministry of Health for project support.

Contributors WST and RB conceived and designed the study, obtained, analysed, interpreted the data, drafted and revised the article. CKL, AHYH and JC conceived the study, participated in the interpretation of results and revised the article. All authors were involved in revising the manuscript critically for important intellectual content and have given final approval of the final version of the manuscript.

Funding WST was funded by the Singapore National Medical Research Council Research (grant number: NMRC/Fellowship/0017/2015) and the Singapore National Healthcare Group. This study was funded by Agency for Integrated Care Singapore (grant number: RCA 16-099), which receives public funding from the Ministry of Health of the Singaporean Government.

Disclaimer The funder has played no role in the study design, analysis or interpretation of data.

Competing interests None declared.

Patient consent for publication Not required

Ethics approval Ethics approval was obtained from theinstitutional review boards of Nanyang Technological University (Ref: IRB-2016-03-010) and the National Healthcare Group's Domain Specific ReviewBoard (Ref: 2016/00739).

Provenance and peer review Not commissioned; externally peer reviewed.

Data sharing statement Access restrictions apply to the data underlying the findings due to national data protection laws and restrictions imposed by the Ethics Committees to ensure data privacy of thestudy participants. As such they cannot be made freely available in the manuscript, the supplemental files, or a public repository. Request for the data may be sent to the national office for Advance Care Planning at livingmatters@aic.sg.

Open access This is an open access article distributed in accordance with the Creative Commons Attribution Non Commercial (CC BY-NC 4.0) license, which permits others to distribute, remix, adapt, build upon this work non-commercially, and license their derivative works on different terms, provided the original work is properly cited, appropriate credit is given, any changes made indicated, and the use is non-commercial. See: http://creativecommons.org/licenses/by-nc/4.0/.

\section{REFERENCES}

1. Murray L, Butow PN. Advance care planning in motor neuron disease: a systematic review. Palliat Support Care 2016;14:411-32.

2. Walczak A, Butow PN, Bu S, et al. A systematic review of evidence for end-of-life communication interventions: Who do they target, how are they structured and do they work? Patient Educ Couns 2016:99:3-16.

3. Weathers E, O'Caoimh R, Cornally N, et al. Advance care planning: a systematic review of randomised controlled trials conducted with older adults. Maturitas 2016;91:101-9.

4. Martin RS, Hayes B, Gregorevic K, et al. The effects of advance care planning interventions on nursing home residents: a systematic review. J Am Med Dir Assoc 2016;17:284-93.

5. Oliver DP. End-of-Life Care in U.S. Nursing homes: a review of the evidence. J Am Med Dir Assoc 2005;6:S20.

6. Detering KM, Hancock AD, Reade MC, et al. The impact of advance care planning on end of life care in elderly patients: randomised controlled trial. BMJ 2010;340:c1345.
7. Ratner E, Norlander L, McSteen K. Death at home following a targeted advance-care planning process at home: the kitchen table discussion. J Am Geriatr Soc 2001;49:778-81.

8. Teno JM, Gruneir A, Schwartz Z, et al. Association between advance directives and quality of end-of-life care: a national study. J Am Geriatr Soc 2007;55:189-94.

9. Schamp R, Tenkku L. Managed death in a PACE: pathways in present and advance directives. J Am Med Dir Assoc 2006; 7:339-44.

10. Ministry of Health. Speech by Mr Gan Kim Yong, Minister for Health, at assisi hospice's charity dinner 2011, pan pacific Singapore. Singapore: Ministry of Health, 2011.

11. Ministry of Health. Speech by Mr Gan Kim Yong, Minister for Health, at Singapore palliative care conference at Singapore. 28. Singapore: Polytechnic Convention Centre, 2014.

12. Ministry of Health. Speech by Mr Gan Kim yong, Minister for Health, at the opening of the asia pacific hospice conference. Singapore: Ministry of Health, 2017.

13. Inter-Ministerial Committee. Report of the inter-ministerial committee on the ageing population. 1999.

14. Finkelstein EA, Bilger M, Flynn TN, et al. Preferences for end-of-life care among community-dwelling older adults and patients with advanced cancer: a discrete choice experiment. Health Policy 2015;119:1482-9.

15. Malhotra C, Farooqui MA, Kanesvaran R, et al. Comparison of preferences for end-of-life care among patients with advanced cancer and their caregivers: A discrete choice experiment. Palliat Med 2015;29:842-50.

16. Low JA, Ng WC, Yap KB, et al. End-of-life issues--preferences and choices of a group of elderly Chinese subjects attending a day care centre in Singapore. Ann Acad Med Singapore 2000;29:50-6.

17. Blackbox Research. Lien foundation survey on death attitudes 2014 March 1, 2015. http://lienfoundation.org/sites/default/files/Death\% 20survey\%20Presser\%20Final\%20-\%20Combined_0.pdf

18. Gomes B, Calanzani N, Gysels M, et al. Heterogeneity and changes in preferences for dying at home: a systematic review. BMC Palliat Care 2013;12:7.

19. Siminoff LA. Incorporating patient and family preferences into evidence-based medicine. BMC Med Inform Decis Mak 2013;13:S6.

20. Hoare S, Morris ZS, Kelly MP, et al. Do Patients Want to Die at Home? A Systematic Review of the UK Literature focused on missing preferences for place of death. PLoS One 2015;10:e0142723.

21. Ditto PH, Jacobson JA, Smucker WD, et al. Context changes choices: a prospective study of the effects of hospitalization on life-sustaining treatment preferences. Med Decis Making 2006;26:313-22.

22. Moorman SM, Carr D, Kirchhoff KT, et al. An assessment of social diffusion in the respecting choices advance care planning program. Death Stud 2012;36:301-22.

23. Chung I. Editor aging issues: advance care planning. Singapore: Singapore Public Health and Occupational Medicine Conference, 2013.

24. How $\mathrm{CH}$, Koh LH. Not that way: advance care planning. Singapore Med J 2015;56:19-22.

25. StataCorp. Stata statistical software: release 12. College Station, TX: StataCorp, 2011

26. Lee A, Pang WS. Preferred place of death-a local study of cancer patients and their relatives. Singapore Med J 1998;39:447-50.

27. Li J, Ngin PM, Teo AC. Culture and leadership in Singapore: combination of the east and the west. 2008.

28. Ang GC, Zhang D, Lim KH. Differences in attitudes to end-of-life care among patients, relatives and healthcare professionals. Singapore Med J 2016;57:22-8

29. $\mathrm{Ng} \mathrm{CW}$, Cheong SK, Govinda Raj A, et al. End-of-life care preferences of nursing home residents: results of a cross-sectional study. Palliat Med 2016;30:843-53.

30. Stamuli E. Health outcomes in economic evaluation: who should value health? Br Med Bull 2011;97:197-210.

31. Wood C, Salter J. A time and a place: what people want at the end of life. Sue Ryder 2013.

32. Kahneman D. Editor determinants of health economic decisions in actual practice: the role of behavioral economics. ispor 10th annual international meeting. Washington, DC, USA: Value in Health, 2005.

33. Townsend J, Frank AO, Fermont D, et al. Terminal cancer care and patients' preference for place of death: a prospective study. BMJ 1990;301:415-7.

34. Barclay S, Arthur A. Place of death: how much does it matter? The priority is to improve end-of-life care in all settings. $\mathrm{Br} J$ Gen Pract 2008;58:229-31. 
35. Agar M, Currow DC, Shelby-James TM, et al. Preference for place of care and place of death in palliative care: are these different questions? Palliat Med 2008;22:787-95.

36. Jimenez G, Tan WS, Virk AK, et al. Overview of systematic reviews of advance care planning: summary of evidence and global lessons. $J$ Pain Symptom Manage 2018;56:436-59.

37. Billings JA, Bernacki R. Strategic targeting of advance care planning interventions: the goldilocks phenomenon. JAMA Intern Med 2014;174:620-4.

38. Hammes BJ, Rooney BL. Death and end-of-life planning in one midwestern community. Arch Intern Med 1998;158:383-90.

39. Auriemma CL, Nguyen CA, Bronheim R, et al. Stability of end-of-life preferences: a systematic review of the evidence. JAMA Intern Med 2014;174:1085-92.

40. van der Steen JT, van Soest-Poortvliet MC, Hallie-Heierman M, et al. Factors associated with initiation of advance care planning in dementia: a systematic review. J Alzheimers Dis 2014;40:743-57.

41. Lunney JR, Lynn J, Foley DJ, et al. Patterns of functional decline at the end of life. JAMA 2003;289:2387-92.

42. Hamel MB, Teno JM, Goldman L, et al. Patient age and decisions to withhold life-sustaining treatments from seriously ill, hospitalized adults. SUPPORT Investigators. Study to Understand Prognoses and Preferences for Outcomes and Risks of Treatment. Ann Intern Med 1999;130:116-25.
43. Hamel MB, Lynn J, Teno JM, et al. Age-related differences in care preferences, treatment decisions, and clinical outcomes of seriously ill hospitalized adults: lessons from SUPPORT. J Am Geriatr Soc 2000:48:S176-82

44. Fukui S, Yoshiuchi K, Fujita J, et al. Japanese people's preference for place of end-of-life care and death: a population-based nationwide survey. J Pain Symptom Manage 2011:42:882-92.

45. Chen CH, Lin YC, Liu LN, et al. Determinants of preference for home death among terminally ill patients with cancer in Taiwan: a crosssectional survey study. J Nurs Res 2014;22:37-44.

46. Fukui S, Fujita J, Tsujimura M, et al. Late referrals to home palliative care service affecting death at home in advanced cancer patients in Japan: a nationwide survey. Ann Oncol 2011;22:2113-20.

47. Foreman LM, Hunt RW, Luke CG, et al. Factors predictive of preferred place of death in the general population of South Australia. Palliat Med 2006;20:447-53.

48. Grande GE, Addington-Hall JM, Todd CJ. Place of death and access to home care services: are certain patient groups at a disadvantage? Soc Sci Med 1998;47:565-79.

49. Thomas C, Morris SM, Clark D. Place of death: preferences among cancer patients and their carers. Soc Sci Med 2004;58:2431-44.

50. Etkind SN, Bone AE, Lovell N, et al. Influences on care preferences of older people with advanced illness: a systematic review and thematic synthesis. J Am Geriatr Soc 2018;66:1031-9. 